
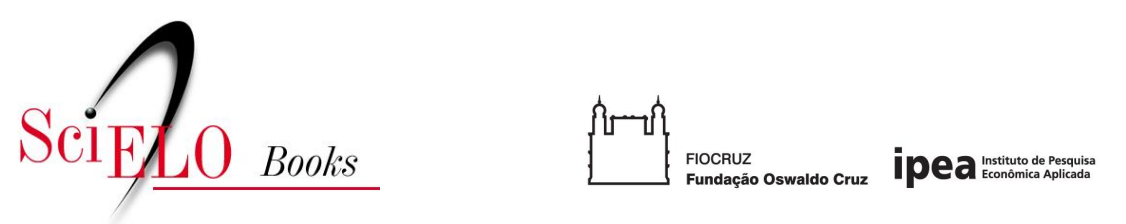

\title{
Infraestrutura científica e tecnológica para apoio ao CEIS - segmento biofarmacêutico
}

\author{
Cristiane Quental \\ Carlos A. Grabois Gadelha \\ José Maldonado \\ Laís Silveira Costa \\ Marco Antonio Vargas
}

\section{SciELO Books / SciELO Livros / SciELO Libros}

QUENTAL, C., et al. Infraestrutura científica e tecnológica para apoio ao CEIS - segmento biofarmacêutico. In FUNDAÇÃO OSWALDO CRUZ. A saúde no Brasil em 2030 - prospecção estratégica do sistema de saúde brasileiro: desenvolvimento produtivo e complexo da saúde [online]. Rio de Janeiro: Fiocruz/Ipea/Ministério da Saúde/Secretaria de Assuntos Estratégicos da Presidência da República, 2013. Vol. 5. pp. 163-193. ISBN 978-85-8110-019-7. Available from SciELO Books <http://books.scielo.org>.

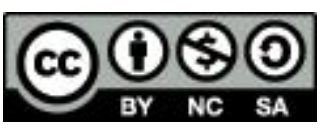

All the contents of this chapter, except where otherwise noted, is licensed under a Creative Commons Attribution-Non Commercial-ShareAlike 3.0 Unported.

Todo o conteúdo deste capítulo, exceto quando houver ressalva, é publicado sob a licença Creative Commons Atribuição Uso Não Comercial - Partilha nos Mesmos Termos 3.0 Não adaptada.

Todo el contenido de este capítulo, excepto donde se indique lo contrario, está bajo licencia de la licencia Creative Commons Reconocimento-NoComercial-CompartirIgual 3.0 Unported. 


\section{Infraestrutura Científica e Tecnológica para Apoio ao CEIS - Segmento Biofarmacêutico}




\title{
INFRAESTRUTURA CIENTÍFICA E TECNOLÓGICA PARA APOIO AO CEIS — SEGMENTO BIOFARMACÊUTICO
}

\author{
Cristiane Quental \\ Carlos A. Grabois Gadelha \\ José Maldonado \\ Laís Silveira Costa \\ Marco Antonio Vargas
}

A infraestrutura científica e tecnológica é elemento fundamental para a inovação no Complexo Econômico-Industrial da Saúde (CEIS). No Brasil, esta infraestrutura é fraca, uma vez que não é demandada pelas empresas do Complexo, que quase não realizam Pesquisa e Desenvolvimento (P\&D). Tanto o investimento dos agentes produtivos do CEIS em P\&D como a infraestrutura científica e tecnológica que o apoia vem progredindo, mas o avanço é lento, apontando, em um cenário inercial, para a ampliação da distância absoluta com relação aos países desenvolvidos e aos demais países emergentes até 2022/2030 no exercício da inovação.

Deve-se enfatizar que o desenvolvimento da infraestrutura científica e tecnológica para apoio ao CEIS é dependente do investimento em P\&D das empresas do Complexo, públicas e privadas, e estará atrelado a ele a não ser que se opte por tornar os centros brasileiros de P\&D competitivos internacionalmente, prestando serviços a empresas estrangeiras que cada vez mais terceirizam esta atividade. Esta opção só seria possível, entretanto, com mudanças no ambiente regulatório e, principalmente, com uma mudança profunda na forma de encarar o setor - como um setor econômico em si, o segmento mais nobre do CEIS no sentido de promover o desenvolvimento. Este é um cenário desejável e viável.

Ressalte-se que apenas um segmento de infraestrutura científica e tecnológica consolidado poderia ser considerado um incentivo para o investimento das empresas em $P \& D$, do contrário, é um entrave. 


\section{I PANORAMA NACIONAL}

\subsection{O Investimento em P\&D\&I em Saúde no Brasil}

O investimento em P\&D em saúde no Brasil foi, no ano de 2005, de US\$ 616,9 milhões de dólares - cerca de 0,38\% do total investido em P\&D em saúde no ano no mundo, US\$ 160,3 bilhões (VIANNA et al., 2009)1.

A Tabela 1 mostra as fontes dos valores investidos no P\&D em saúde no Brasil. O financiamento é majoritariamente governamental ( $74,4 \%$, em média, nos três anos), com um componente privado $(23,3 \%$ ) bem abaixo daquele registrado nos países mais desenvolvidos, que chegou ao patamar de 58\%, em média, em 2005 (BURKE e MATLIN, 2008).

Tabela 01. Investimento em P\&D em saúde no Brasil, por fonte, 2003-2005 (US\$ M)

\begin{tabular}{l|r|r|r|r|r}
\hline \multicolumn{1}{c|}{ Fontes } & \multicolumn{1}{c|}{2003} & 2004 & \multicolumn{1}{c|}{2005} & Média anual & \multicolumn{1}{c}{$\%$} \\
\hline Governo Federal & 169,4 & 204,8 & 301,5 & 225,2 & 45,6 \\
\hline MS & 37,0 & 46,0 & 82,8 & 55,3 & 11,2 \\
\hline MCT & 37,4 & 55,6 & 83,6 & 58,9 & 11,9 \\
\hline ME & 92,8 & 100,9 & 132,4 & 108,7 & 22,1 \\
\hline Outros ministérios & 2,2 & 2,3 & 2,6 & 2,4 & 0,4 \\
\hline Gov. Estaduais & 125,1 & 133,8 & 167,9 & 142,3 & 28,8 \\
\hline Secr Educação & 83,7 & 87,7 & 105,8 & 92,4 & 18,7 \\
\hline FAPs & 37,9 & 42,2 & 57,9 & 46,0 & 9,3 \\
\hline Outras inst.est. & 3,4 & 3,8 & 4,3 & 3,8 & 0,8 \\
\hline Setor Público & 294,5 & 338,5 & 469,4 & 367,5 & 74,4 \\
\hline Setor Privado* & 104,3 & 109,2 & 131,7 & 115,1 & 23,3 \\
\hline Org. Internacionais & 8,2 & 9,8 & 15,8 & 11,3 & 2,3 \\
\hline Total & 407,0 & 457,6 & 616,9 & 493,8 & 100,0 \\
\hline
\end{tabular}

* Indústria farmacêutica, de equipamentos de saúde e ONGs.

Fonte: Vianna et al, 2009.

1 Compare-se este valor ao investimento da Pfizer em P\&D no ano anterior, de US\$ 7,7 bilhões e de outras tantas multinacionais farmacêuticas (Parexel, 2005). 
A Tabela 2 apresenta os setores de aplicação desses recursos. As universidades são as grandes beneficiárias do investimento público. Guimarães (2006) ressalta, entretanto, que o financiamento governamental é voltado principalmente para o pagamento dos salários de pesquisadores e professores (55\%) e de bolsas de formação e de produtividade (30\%), restando apenas 15\% para o fomento à pesquisa propriamente dita.

Tabela 02. Investimento em P\&D em saúde no Brasil, por usuário, 2003-2005 (US\$ M)

\begin{tabular}{|c|c|c|c|c|c|}
\hline Usuário & 2003 & 2004 & 2005 & Média anual & $\%$ \\
\hline Governo Federal & 33,5 & 41,1 & 58,0 & 44,2 & 8,9 \\
\hline MS & 30,3 & 34,4 & 50,3 & 38,3 & 7,8 \\
\hline Outros ministérios & 3,3 & 6,7 & 7,8 & 5,9 & 1,1 \\
\hline Gov. Estaduais / Municipais & 12,9 & 15,6 & 20,1 & 16,2 & 3,3 \\
\hline Setor Público & 46,4 & 56,7 & 78,2 & 60,4 & 12,2 \\
\hline Universidades/IPs & 268,5 & 304,3 & 416,0 & 329,6 & 66,7 \\
\hline Setor Privado & 90,9 & 96,5 & 122,7 & 103,4 & 20,9 \\
\hline Ind. farmacêutica & 66,0 & 69,2 & 83,4 & 72,9 & 14,7 \\
\hline Ind. equip. médicos & 24,2 & 25,3 & 30,6 & 26,7 & 5,4 \\
\hline Outras inst privada & 0,7 & 2,0 & 8,7 & 3,8 & 0,8 \\
\hline Org.Internacionais & 1,1 & 1,2 & 1,3 & 1,2 & 0,2 \\
\hline Total & 407,0 & 457,6 & 616,9 & 493,8 & 100,0 \\
\hline
\end{tabular}

Fonte: Vianna et al, 2009.

Este quadro reflete a diretriz da política de Ciência e Tecnologia (C\&T) vigente na segunda metade do século XX no Brasil, de investir maciçamente na formação de recursos humanos, especialmente de novos doutores, para fortalecimento do sistema nacional de pós-graduação. "Os dados disponíveis demonstram, sobremaneira, que é no interior do Sistema Nacional de Pós-graduação que, basicamente, ocorre a atividade de pesquisa científica e tecnológica brasileira" (CAPES, 2005, apud GUIMARÃES, 2011).

\section{2 | A Produção Científica em Saúde}

A produção científica brasileira como um todo tem crescido muito em termos do número de artigos publicados em revistas indexadas internacionalmente. O País passou de $0,44 \%$ da produção mundial de artigos científicos indexados pelo 
Institute for Scientific Information (ISI) em 1981 (27ª posição) para 2,69\% em 2009 (13 ${ }^{a}$ posição). Os indicadores de qualidade da pesquisa realizada também vêm crescendo, embora em um ritmo menor que os indicadores de quantidade (CRUZ e CHAIMOVICH, 2010).

Certamente o Brasil está entre os países de maior crescimento no número de publicações indexadas. Mas enquanto o Brasil multiplicou por 15 o número de artigos indexados entre 1981 e 2009, a Coréia do Sul multiplicou por 159 e a China por 97 (Tabela 3). A China passa, assim, a ocupar a $2^{a}$ posição no ranking dos países com maior número de publicações indexadas, atrás apenas dos EUA, como mostra a Tabela 4.

Este crescimento acompanha o número de doutores formados, sendo que mais de $90 \%$ dos artigos publicados em periódicos científicos indexados internacionalmente foi produzida em universidades públicas, a maior parte delas concentrada na região sudeste.

Embora o fortalecimento da pós-graduação no país tenha sido feito de forma horizontal, visando à capacitação científica em todas as áreas do conhecimento, sem prioridades bem definidas (GUIMARÃES, 2006), "o desempenho da ciência brasileira carece ainda da uniformidade observada nos países mais desenvolvidos. Muitas áreas, com capacitação de recursos humanos ainda não consolidada, apresentam desempenho modesto" (GUIMARÃES, 2004, p.304). O crescimento apresentado baseiase principalmente nas áreas científicas mais consolidadas, não sendo homogêneo nem entre as áreas, nem entre as suas subáreas.

Tabela 03. Países com maior variação percentual do número de artigos publicados em periódicos científicos indexados pela Thomson/ISI, 1981/2009

\begin{tabular}{rl|r|r|r}
\hline \multicolumn{1}{l|}{ Países } & \multicolumn{1}{|c|}{1981} & $\mathbf{2 0 0 9}$ & Variação \% \\
\hline 1 & Coréia do Sul & 241 & 38.651 & $15.937,8$ \\
\hline 2 & China & 1.204 & 118.108 & $9.709,6$ \\
\hline 3 & Turquia & 337 & 22.037 & $6.439,2$ \\
\hline 4 & Taiwan & 531 & 24.442 & $4.503,0$ \\
\hline 5 & Brasil & 1.949 & 32.100 & $1.547,0$ \\
\hline 6 & Espanha & 3.290 & 44.324 & $1.247,2$ \\
\hline 7 & Itália & 7.639 & 51.606 & 435,4 \\
\hline 8 & Holanda & 4.825 & 19.513 & 310,7 \\
\hline 9 & Polônia & 10.782 & 38.599 & 258,0 \\
\hline 10 & Austrália & & 30.204 & 3,4 \\
\hline
\end{tabular}

Fonte: National Science Indicators, Thomson Reuters / Science. Elaboração: Capes (BRASIL, 2011). 
Tabela 04. Países com maior número de artigos publicados em periódicos científicos indexados pela Thomson/ISI, 2009

\begin{tabular}{|c|c|c|}
\hline & País & 2009 \\
\hline 1 & Estados Unidos da América & 341.038 \\
\hline 2 & China & 118.108 \\
\hline 3 & Reino Unido & 92.628 \\
\hline 4 & Alemanha & 89.545 \\
\hline 5 & Japão & 78.930 \\
\hline 6 & França & 65.301 \\
\hline 7 & Canadá & 55.534 \\
\hline 8 & Itália & 51.606 \\
\hline 9 & Espanha & 44.324 \\
\hline 10 & Índia & 40.250 \\
\hline 11 & Coréia do Sul & 38.651 \\
\hline 12 & Austrália & 38.599 \\
\hline 13 & Brasil & 32.100 \\
\hline 14 & Holanda & 30.204 \\
\hline 15 & URSS/Rússia & 30.178 \\
\hline 16 & Taiwan & 24.442 \\
\hline 17 & Turquia & 22.037 \\
\hline 18 & Suíça & 21.800 \\
\hline 19 & Suécia & 19.611 \\
\hline 20 & Polônia & 19.513 \\
\hline
\end{tabular}

Fonte: National Science Indicators, Thomson Reuters / Science. Elaboração: Capes (BRASIL, 2011).

Observe-se que as áreas mais dinâmicas em termos da quantidade de artigos publicados em periódicos de circulação internacional no período 1998-2008 foram as ciências da saúde e as ciências biológicas (Gráfico 1). Juntas, estas duas áreas são responsáveis por metade da produção científica brasileira de circulação internacional (Gráfico 2), embora sejam compostas por apenas 29\% dos grupos de pesquisa registrados no diretório do CNPq e 36\% dos doutores (CNPq, 2010). 
Gráfico 01. Número de artigos de doutores brasileiros publicados em periódicos de circulação internacional, 1998-2008

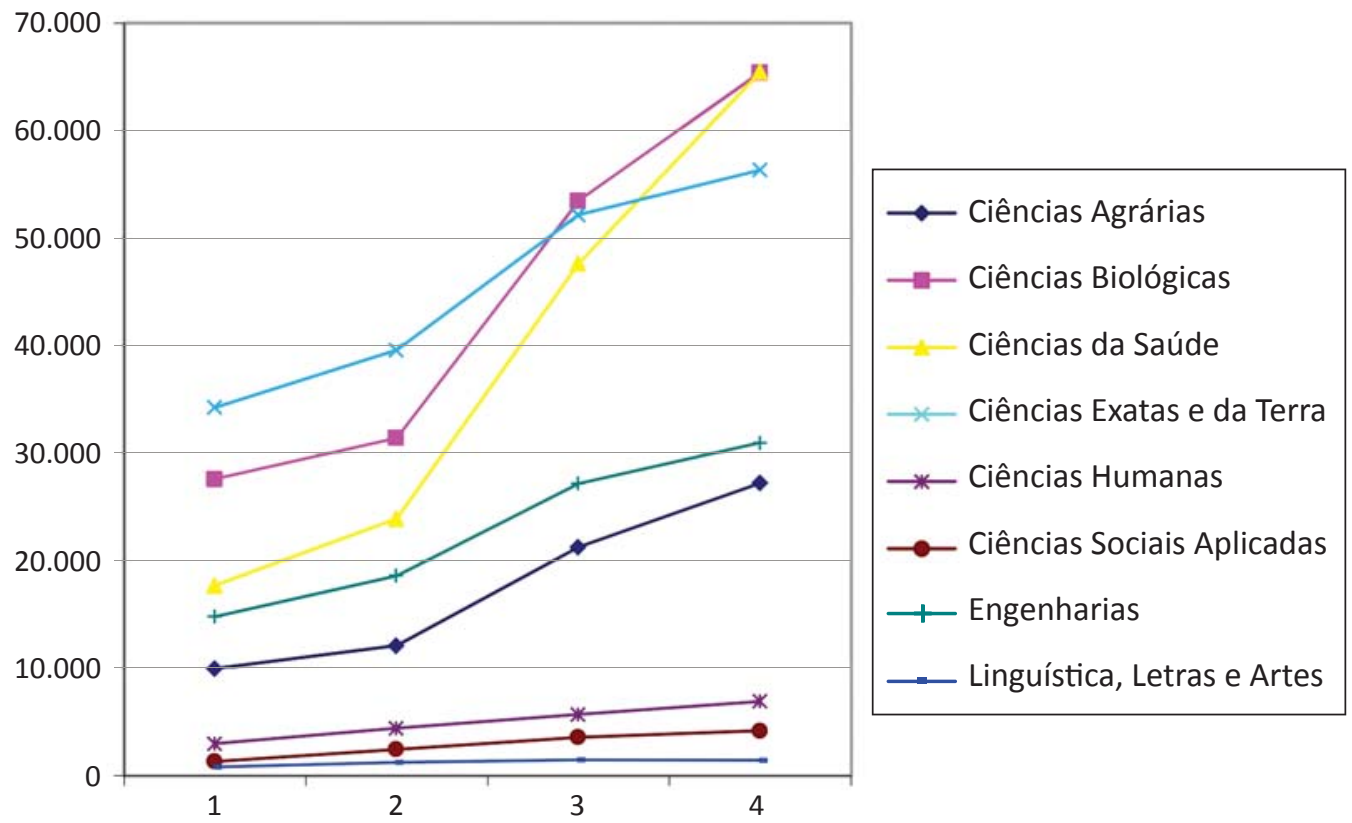

Nota: 1: 1998-2001; 2: 2000-2003; 3: 2003-2006; 4: 2005-2008

Fonte: A partir de dados MCT (BRASIL, 2011).

Gráfico 02. Número de artigos brasileiros publicados em periódicos de circulação internacional por grande área do conhecimento, 2005-2008

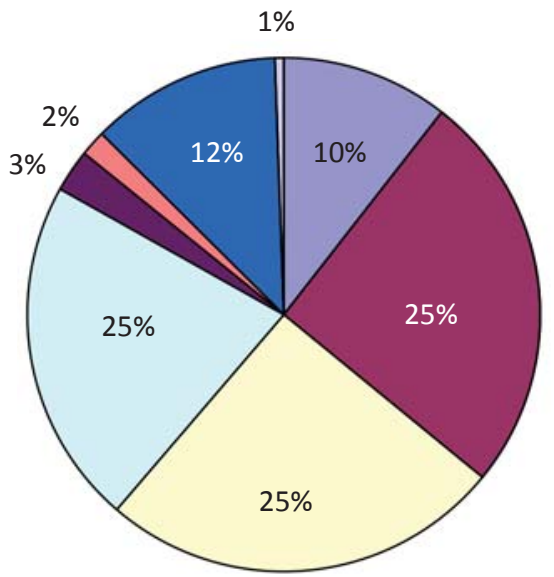

Ciências Agrárias

$\square$ Ciências Biológicas

$\square$ Ciências da Saúde

$\square$ Ciências Exatas e da Terra

Ciências Humanas

Ciências Sociais Aplicadas

Engenharias

Linguística, Letras e Artes

Fonte: a partir de dados MCT (BRASIL, 2011).

Guimarães (2006), entendendo a pesquisa em saúde como um campo de aplicação e não como um conjunto de disciplinas, verificou que cerca de um terço dos 
grupos de pesquisa registrados no Diretório dos Grupos de Pesquisa do CNPq no censo de 2004 tem pelo menos uma linha de pesquisa vinculada ao setor de atividade "saúde humana”.

Grupos de pesquisa oriundos de todas as grandes áreas do conhecimento possuem linhas de pesquisa vinculadas ao setor de atividade "saúde humana”. Cerca de 50\% dos grupos provêm das ciências da saúde (20\% da medicina) e pouco menos de $25 \%$ das ciências biológicas. O quarto restante provém das demais grandes áreas do conhecimento (GUIMARÃES, 2006).

Deve-se destacar que, a exemplo de outras atividades econômicas, a pesquisa em saúde está fortemente concentrada na região Sudeste (60\% da produção), ficando a região Sul com 19\%, Nordeste com 13\%, Centro-Oeste com 6\% e Norte com 3\% (BRASIL, 2011).

\section{3 | Desenvolvimento Tecnológico}

Os resultados da pesquisa realizada, entretanto, não se transformam em inovações, e, assim, não chegam à sociedade. Ainda considerando as patentes como um indicador muito parcial de inovação, verifica-se que as patentes solicitadas por brasileiros nos Estados Unidos da América (EUA) em 2009 somaram apenas 464 pedidos, um número 9 vezes maior que as 53 patentes solicitadas em 1980, mas pequeno comparativamente aos 32.100 artigos publicados no ano. A China, por sua vez, registrou 6.879 pedidos de patente em 2009, número 982 vezes maior que as sete patentes solicitadas em 1980, representando também um percentual bem maior com relação ao número de artigos publicados em 2009, 118.108 (BRASIL, 2011).

A situação não é diferente quando se enfoca o Complexo Industrial da Saúde, pelo baixo interesse das empresas brasileiras do Complexo nas atividades de $\mathrm{P} \& \mathrm{D}$ como forma de inovação. Isolada, a academia volta-se principalmente à pesquisa básica, na qual possui competência, não avançando na direção das etapas subsequentes do processo de $\mathrm{P} \& \mathrm{D}$, em direção a novos produtos e processos. Como mostra o trabalho de Bomtempo e Baetas (2005) que analisa a P\&D no Brasil na área de vacinas humanas, o número de grupos de pesquisa atuantes e sua competência vão se reduzindo à medida que o processo avança em direção a um produto.

Assim, a capacitação e a infraestrutura nas etapas intermediárias dos processos de desenvolvimento de produtos - estudos pré-clínicos, scaleup, produção de lotes piloto - são escassas. Deste modo, se verifica um vazio que impede que os resultados da pesquisa se transformem em produtos, dificultando as 
relações da academia com a indústria. Sintoma desta situação, a regulamentação do setor é incipiente, o que acaba se transformando em mais um obstáculo imposto ao desenvolvimento do segmento no Brasil, não só pela insegurança que agrega ao investimento, mas também porque dificulta a inserção deste segmento na institucionalidade global, fundamental em um segmento internacionalizado como o farmacêutico e no qual os investimentos só se justificam se são voltados para o mercado global.

Existe, entretanto, expertise no Brasil em ensaios clínicos, ainda que grupos testem principalmente produtos estrangeiros. Assim, esta expertise é maior para a execução que para o desenho dos ensaios.

\section{4 | Ensaios Pré-Clínicos}

Os ensaios pré-clínicos são um dos elos fracos na cadeia de desenvolvimento de novos produtos no segmento da saúde no Brasil. Pela posição estratégica que ocupam na cadeia — na interface entre a pesquisa e o desenvolvimento - seu fortalecimento tem sido objeto de ação política recente de ciência e tecnologia em saúde. Testes pré-clínicos se referem a todos os ensaios in vitro ou in vivo e, mais recentemente, in silico realizados para a comprovação da eficácia e segurança de drogas candidatas descobertas na etapa de pesquisa, antes de serem testadas em humanos. De forma geral, podem-se dividir os estudos pré-clínicos em três grandes grupos, os farmacológicos, os farmacocinéticos e os toxicológicos:

- A farmacologia fornece as primeiras informações sobre o potencial terapêutico do medicamento. Outras informações obtidas por meio desses estudos incluem o modo de ação do medicamento, os seus possíveis efeitos secundários, possíveis efeitos negativos sobre os sistemas vitais (principalmente, os sistemas nervoso, cardiovascular e respiratório) e interações com outros medicamentos.

- Com os estudos de farmacocinética podem-se obter informações sobre absorção, cinética no plasma, metabolismo e excreção da substância ativa, dentre outras, nos animais. A comparação desses dados pré-clínicos com os dados de farmacocinética clínicos é crucial para a extrapolação dos resultados do animal para o homem.

- Os estudos toxicológicos fornecem informações sobre uma série de aspectos relacionados à segurança dos pacientes: toxicidade aguda, toxicidade subaguda, subcrônica e crônica, mutagenicidade, carcinogenicidade, toxicidade sobre a função reprodutora e risco de desenvolvimento de malformações fetais, dentre outros. (BARREIRO, 2010): 
Os testes toxicológicos são o principal componente do desenvolvimento pré-clínico, constituindo, em média, 50\% dos custos totais (KREGER e FELDMAN, 2004). Os testes toxicológicos podem demorar dias ou anos, se a droga em teste for de uso ocasional ou contínuo. "A toxicologia é uma etapa bastante delicada que pode absolver ou condenar, de vez, uma molécula” (TORRES, 2009). Eliminando-se precocemente moléculas candidatas sem o perfil de biodisponibilidade adequado ou tóxicas, evita-se o insucesso nas etapas subsequentes, de ensaios clínicos, quando um grande volume de recursos já terão sido gastos. Vale lembrar que as principais causas de abandono de compostos candidatos ao longo de todo o processo de desenvolvimento de novas drogas são o perfil de disponibilidade inadequado (46\% dos casos) e a toxicidade (40\%) (KALORAMA, 2006).

Os estudos pré-clínicos são intensivos em ciência e requerem um alto nível de investimento em equipamento e pessoal especializado, como doutores em toxicologia e em patologia, que são escassos, além de facilidades para criação e teste em animais. Melhores resultados são obtidos quando os cientistas têm experiência em áreas terapêuticas, tipos de compostos, tecnologias ou modelos animais (SAHOO, 2006). A escala é, assim, necessária para diluir os altos custos fixos das atividades. Estes estudos devem ser conduzidos seguindo as boas práticas de laboratório (BPLs); os testes realizados devem seguir os protocolos de agências reconhecidas; e os animais utilizados devem ser padrão de qualidade definido (PIERONI et al., 2009).

Estas são barreiras à entrada que levam as novas empresas do setor farmacêutico e, crescentemente, as já estabelecidas, a terceirizar essas atividades. As contract research organizations (CROs) que oferecem estudos pré-clínicos são frequentemente especializadas em determinados tipos de estudo. Em 2005, cerca de 15\% das avaliações pré-clínicas foram terceirizadas (SAHOO, 2006).

Reunião realizada em junho de 2006 com a presença de 43 representantes de universidades, institutos de pesquisa e empresas envolvidas com a questão (HOSPITAL SÍRIO LIBANÊS, 2006) traçou um diagnóstico da situação das competências instaladas em pesquisas pré-clínicas no Brasil:

- Não existe clareza sobre a real situação dos ensaios préclínicos no Brasil. Existem grupos instalados, que não realizam, entretanto, todos os testes necessários de modo a atender as exigências, principalmente internacionais, bem como não possuem, na sua grande maioria, certificação em BPL.

- Especificamente em toxicologia, foram identificados alguns estudos que ainda não são realizados no país ou o são incipientemente: safety pharmacology, farmacocinética, alguns estudos de genotoxicidade, estudos de toxicidade em primatas. 
- A disponibilidade e a qualidade das diversas espécies animais, sejam roedores ou não, são insuficientes para atender a uma demanda crescente de ensaios in vivo. Ainda, alertou-se para a necessidade testes alternativos ao uso de modelos animais.

- Existe carência de recursos humanos, especialmente em patologia experimental e diagnóstico por imagem.

Deve-se ressaltar que as BPLs não são necessárias para a pesquisa acadêmica relacionada à fase de descoberta de novas moléculas. Elas passam a ser imprescindíveis quanto se entra na fase dos testes pré-clínicos que servirão para embasar o desenvolvimento de um produto a ser colocado no mercado. Não é esperado, assim, que laboratórios acadêmicos as implementem.

O INMETRO, através de sua área de acreditação de laboratórios, já reconhece o uso de BPLs para uma série de ensaios voltados para produtos farmacêuticos - estando cerca de meia dúzia de centros de pré-clínicos brasileiros reconhecidos. A falta de regulamentação deste segmento, entretanto, ainda é considerada um gargalo que dificulta o caminho dos projetos em direção a produtos.

Com relação aos animais de laboratório, vale dizer que não estão disponíveis para aquisição no mercado nacional. Os animais utilizados aqui são criados pelas próprias organizações que os utilizam - universidades, institutos de pesquisa, centros de pré-clínicos - com qualidade bastante diferenciada, em geral baixa. Nessas organizações, a criação de animais não é considerada central e é subfinanciada. Como têm que ser autossuficientes na produção de animais para sua pesquisa, as organizações produzem uma grande variedade de espécies, tornando-se altamente ineficientes. Quando são necessários animais de qualidade superior, frequentemente se recorre à importação — operação complexa burocraticamente, que afeta os animais, além de ser necessário mantê-los em quarenta. As tentativas de atrair empresas estrangeiras para se instalarem no Brasil não têm se mostrado viáveis, pela baixa demanda nacional e regional.

\section{Escalonamento da produção / Plantas piloto}

Plantas piloto para scale up e produção de lotes para os ensaios clínicos também são consideradas um gargalo. Essa atividade incorpora uma dimensão industrial, pesquisa de processos e de métodos analíticos para a produção, $e$ a maioria dos processos envolve interações complexas de fatores biológicos, químicos e físicos, o que demanda uma visão sistêmica de desenvolvimento de produto. Além disso, os requisitos de Boas Práticas de Fabricação (GMP) correntes devem ser seguidos na produção dos lotes que serão utilizados nos testes clínicos (BAETAS et al., 2008). 
Poucas são as iniciativas em andamento de construção de instalações dedicadas, em GMP, para desenvolvimento e produção de lotes para estudos clínicos. Destacam-se os produtores públicos de vacinas - Biomanguinhos e Butantan - e algumas pequenas empresas de base tecnológica, constituídas por profissionais experientes provenientes de determinados grupos universitários (BAETAS et al., 2008).

\section{5 | Ensaios Clínicos}

Os ensaios clínicos são a etapa mais cara e demorada do processo de desenvolvimento. Envolvem, em uma primeira etapa — Fase I, a avaliação da tolerância/ segurança do medicamento, em um número restrito de voluntários sadios; a partir de resultados satisfatórios nesta primeira etapa, passa-se a uma segunda etapa Fase II - na qual são realizados testes em voluntários portadores da patologia, ainda em número restrito, para avaliar a eficácia terapêutica; o sucesso nesta fase permite que se passe à Fase III, na qual são realizados estudos terapêuticos ampliados, para determinação do risco-benefício do tratamento.

A participação dos testes clínicos nos custos totais do desenvolvimento de uma nova droga estimada por DiMasi et al. (2003) é compatível com as estimativas agregadas pela empresa Fast Trade Systems Inc. (PAREXEL, 2005), segundo as quais os ensaios clínicos representariam cerca de $53 \%$ dos gastos totais com P\&D no mundo. Cerca de $70 \%$ dos ensaios clínicos para novos medicamentos são financiados pela indústria (BODENHEIMER, 2000).

Os testes clínicos para fins de registro de medicamentos realizados no Brasil cresceram muito na segunda metade dos anos 1990. A grande maioria dos estudos realizados, entretanto, refere-se à participação de centros de pesquisa brasileiros na condução de pesquisas clínicas para o desenvolvimento de novos fármacos, patrocinadas por empresas estrangeiras, integrando redes internacionais de ensaios clínicos sob supervisão de instituições de pesquisa estrangeiras (LOUSANA, 2004).

Este movimento ocorre no bojo de um processo de globalização da atividade apontado pela Mercer Management Consulting (2001) como resultante do crescimento no número e no tamanho dos ensaios clínicos, tornando o recrutamento de pacientes um fator crítico para a pesquisa, especialmente no caso de doenças menos prevalentes. Várias têm sido as estratégias da indústria para lidar com esta questão, incluindo maior divulgação de seus ensaios, maior investimento no recrutamento de investigadores, incorporando um maior número de centros, em um maior número de países para expandir sua base de participantes potenciais.

Muito contribuiu para isso a implantação do atual sistema regulatório ético, com a criação dos Comitês de Ética em Pesquisa (CEPs) institucionais e da Comissão Nacional de Ética em Pesquisa (Conep), e sanitário, com a criação da Agência 
Nacional de Vigilância Sanitária (Anvisa) e de políticas ativas nestas áreas. Além da existência de um CEP aprovado, as empresas valorizam a infraestrutura dos centros em termos de instalações, equipamentos, equipe treinada e com funções especializadas, tempo de resposta (associado ao número de pacientes que pode acessar e ao número de estudos que já estão na fila) e qualidade (QUENTAL e SALLES FILHO, 2006).

Os estudos mais demandados pelas empresas estrangeiras são estudos de fase III (Tabela 5) — estudos com um número grande de sujeitos, envolvendo diversos países, de vários continentes, seguindo o mesmo protocolo e com o mesmo cronograma de execução. Isso permite que os dados sejam aceitos mundialmente e sejam submetidos às autoridades simultaneamente em todos os países do mundo, para que o lançamento também seja quase simultâneo. As demandas são colocadas pelas filiais das multinacionais aqui instaladas ou por meio de Contract Research Organizations (CROs), empresas que organizam e gerenciam sua execução, também com estruturas internacionalizadas que atendem não só as multinacionais como as empresas de biotecnologia, que não têm estrutura para isso (QUENTAL e SALLES FILHO, 2006).

Tabela 05. Número de comunicados especiais por fases de estudo, 2002-2005

\begin{tabular}{l|r|r|r}
\multicolumn{1}{c|}{ FASES } & 2003 & 2004 & 2005 \\
\hline Fase 1 & 9 & 23 & 19 \\
\hline Fase 2 & 131 & 111 & 169 \\
\hline Fase 3 & 572 & 629 & 662 \\
\hline Fase 4 & 107 & 116 & 88 \\
\hline Estudo Observacional & & 2 & 2 \\
\hline Total & $\mathbf{8 1 9}$ & $\mathbf{8 8 1}$ & $\mathbf{9 4 0}$ \\
\hline
\end{tabular}

Fonte: Anvisa, 2007.

A capacitação nacional em ensaios clínicos é alta na realização de ensaios fase III e razoável na fase II, que demanda competências similares. Em 2006, existiam cerca de 300 sites de pesquisa atuando com ensaios clínicos para avaliação de medicamentos no Brasil. Os dez maiores centros concentravam cerca de 40\% dos ensaios realizados, os vinte primeiros, $60 \%$ e os $40 \%$ restantes estavam dispersos em um grande número de centros, sendo que cerca de cinquenta deles concentravam a maior parte das atividades realizadas (QUENTAL e SALLES FILHO, 2006).

Os centros que concentram os ensaios clínicos estão localizados em algumas das maiores universidades e institutos de pesquisa nacionais, em São Paulo, Rio de Janeiro, Rio Grande do Sul e Paraná. Desenvolveram, além da competência médica que lhes serve de base e de sua fonte de pacientes, uma estrutura de pesquisa, com 
maior ou menor grau de especialização de pessoal por função nas equipes envolvidas (p.ex. gerente de projeto, responsável pelos assuntos regulatórios, controle de qualidade, etc), mas com ênfase nas Boas Práticas de Pesquisa Clínica. O Brasil dispõe hoje de um razoável número de centros com nível de competência na execução de ensaios fases II/ III, atendendo plenamente à indústria multinacional (QUENTAL e SALLES FILHO, 2006).

Esta capacitação, entretanto, é maior na execução da pesquisa que no seu desenho. Em geral, os centros realizam a parte clínica dos ensaios para as multinacionais contratantes a partir de protocolos vindos do exterior. Apesar do desenvolvimento tecnológico limitado, o domínio da execução desta fase é fundamental em qualquer processo de ensaio clínico com medicamentos e, é importante destacar, tem sido a base para alavancar o processo de acumulação de competências em ensaios clínicos. Ainda, os recursos arrecadados permitem a manutenção e treinamento permanente da equipe especializada e sua disponibilidade para empreender projetos de maior interesse para a equipe e para o país. A capacitação adquirida na execução tem permitido aos investigadores brasileiros começar a participar da elaboração dos protocolos de pesquisa, seja por convite do investigador principal do projeto multicêntrico, seja por submissão de projeto próprio à indústria para financiamento, sendo interessante apontar movimentos observados de submissão de projetos até de fase I (propondo investigar novos usos para o produto, diferentes dos estudados pela patrocinadora, voltados para a realidade nacional).

Este perfil, entretanto, é diferente daquele demandado pelos empreendimentos nacionais, que inclui competências no desenho dos ensaios, e precisaria ser ajustado para atendê-los, em caso da demanda nacional aumentar, uma vez que os projetos em desenvolvimento no momento são poucos.

Além de poucos, os projetos de inovação das empresas nacionais são voltados principalmente para novas combinações de moléculas já no mercado, ou para testar no Brasil moléculas em parceria com empresas estrangeiras. Assim, tanto no caso dos produtores, quanto das CROs nacionais entrevistados, ficou evidenciada uma maior capacitação na fases II, III e IV e uma menor capacitação na fase I, também para as empresas nacionais contratantes (QUENTAL e SALLES FILHO, 2006).

Já a capacitação para realizar a fase I é bem mais rara e restringe-se a alguns centros de excelência, não estando disponível para todas as patologias. As competências envolvidas são bem diferentes daquelas para a fase III, como em farmacologia, mais especificamente para o desenvolvimento de metodologias analíticas de farmacocinética e farmacodinâmica, para indicar o processamento do medicamento no organismo. Exige também infraestrutura laboratorial sofisticada, além da capacitação médica para fase I, que inclui identificação de efeitos colaterais, identificação de dose adequada etc. Esta capacitação, mais tácita, tem sido mais difícil de desenvolver, não estando disponível facilmente no mercado brasileiro. 
Após um rápido crescimento, na segunda metade dos anos 1990, os ensaios clínicos realizados por empresas estrangeiras no Brasil se estabilizaram. Embora haja uma estabilização no número de ensaios clínicos fase III realizados globalmente, os centros nacionais entendem que poderiam estar atendendo a uma demanda maior não fosse o tempo que o projeto leva para ser aprovado no sistema CEP/Conep, fazendo com que os centros nacionais percam oportunidades para os congêneres do Leste Europeu, da América Latina e da Ásia. No Brasil o tempo de aprovação de um projeto para testes com novos medicamentos levaria em média 24 semanas, contra um período médio de 6 a 10 semanas no mundo desenvolvido (com exceção do Reino Unido, onde este prazo é de 20 semanas) (QUENTAL e SALLES FILHO, 2006). Algumas bases de dados apresentam a Argentina com um número crescente de ensaios, já tendo ultrapassado o Brasil.

\section{6 | Bioequivalência}

O maior número de testes clínicos realizados pela indústria nacional são os estudos de bioequivalência para alcance do status de medicamento genérico. No Brasil, a intercambialidade com o medicamento de referência é assegurada por testes de equivalência farmacêutica (nos quais se procura mostrar que o medicamento genérico contém o mesmo fármaco, na mesma quantidade e forma farmacêutica que o medicamento de referência) e bioequivalência (nos quais se procura mostrar que o medicamento genérico e o medicamento de referência, ao serem administrados na mesma dose e nas mesmas condições experimentais, não apresentam diferenças estatisticamente significativas em relação à biodisponibilidade, avaliada a partir da velocidade e extensão de absorção do princípio ativo, a partir de sua circulação sistêmica ou sua excreção na urina) realizados por laboratórios credenciados pela Anvisa. Sua qualidade é garantida pelo monitoramento das unidades produtivas quanto ao atendimento das Boas Práticas de Fabricação — BPF.

Em julho de 2010 existiam vinte e cinco centros nacionais certificados pela Anvisa para a realização de testes de bioequivalência no Brasil². Dezessete deles (72\%) estão localizados no estado de São Paulo (os demais em CE, GO, MG, PR, PE, RJ e RS). Dezessete deles (72\%) são privados, os demais estando localizados em universidades ou hospitais universitários (ANVISA, 2010).

A demanda por testes de bioequivalência e biodisponibilidade é crescente, tendo sido realizados no Brasil cerca de duzentos ensaios no ano de 2007 (último dado disponibilizado pela Anvisa), como mostra a Tabela 6.

2 A Anvisa certifica também centros estrangeiros, contando atualmente com 26 centros certificados no exterior, $62 \%$ deles localizados na Índia. Os centros são certificados a partir da comprovação de cumprimento das normais nacionais e internacionais de pesquisa clínica e dos regulamentos técnicos vigentes pertinentes aos ensaios de biodisponibilidade / bioequivalência emitidos pela Anvisa. 
Tabela 06. Número de estudos de bioequivalência realizados no Brasil,2002-2007

\begin{tabular}{c|c|c|c|c|c|c}
\hline Centros & 2002 & 2003 & 2004 & 2005 & 2006 & 2007 \\
\hline Total de estudos realizados & 119 & 167 & 140 & 192 & 213 & 204 \\
\hline
\end{tabular}

Fonte: Anvisa, 2007.

Essa demanda, entretanto, está sendo atendida de forma bastante concentrada por um pequeno número de centros de pesquisa, enquanto a grande maioria não está conseguindo se colocar no mercado, apresentando capacidade ociosa. Os três centros que mais realizaram ensaios no período 2002-2007 foram responsáveis por 47\% dos ensaios realizados; os seis primeiros, por 77\%; os dez primeiros, por $92 \%$ (ANVISA, 2007).

Esta concentração na oferta reflete a concentração da capacitação técnica, especialmente no desenvolvimento das metodologias analíticas a serem utilizadas, em alguns centros privados e nas universidades. Nas universidades, entretanto, o tempo de realização dos estudos costuma ultrapassar o tempo habitual de trabalho dos centros privados - sendo o tempo uma variável importante no segmento dos genéricos.

\section{2 | PERSPECTIVAS PARA 2022-2030}

\section{1 | Incentivos à Inovação e à Superação dos Gargalos da Infraestrutura Científica e Tecnológica de Apoio ao CEIS}

Para enfrentar esta situação, e com a retomada da ideia da necessidade de uma política industrial no país, a política de C\&T está mudando, encarando como desafios não só manter o crescimento quantitativo e qualitativo da produção científica, mas também aumentar a taxa de incorporação do conhecimento científico e tecnológico em novos processos e produtos colocados à disposição da sociedade.

Esse conjunto de mudanças destaca três aspectos: 1) aumento da capacidade de indução, no sentido de conciliar mérito científico e prioridades, definidas por atores internos e externos à comunidade científica; 2) ênfase ao componente tecnológico e busca de inovação, deslocando o tradicional balanço observado na pesquisa realizada no país, predominantemente científica; 3) reforço do componente empresarial, estimulando diretamente empresas ou contemplando sua associação com grupos e instituições de pesquisa (GUIMARÃES, 2006, p.5). 
Nesse sentido, vem-se estabelecendo políticas, avanços no marco regulatório e disponibilização de financiamento para todas as etapas do processo de inovação. Os resultados alcançados, entretanto, ainda são modestos.

\subsection{Mudança do Paradigma da Política Industrial, Científica e Tecnológica}

As novas políticas estão perfeitamente articuladas em um corpo integrado que inclui a Política Industrial, Tecnológica e de Comércio Exterior - PITCE (BRASIL, 2003) que marca o relançamento da ideia de política industrial no Brasil e a Política de Desenvolvimento Produtivo - PDP (BRASIL, 2008a), que a atualiza e aprofunda; e as políticas setoriais que atingem o CEIS, notadamente a Política Nacional de Biotecnologia (BRASIL, 2007a), o Programa Mais Saúde 2008-2011 (BRASIL, 2007b), O Plano de Ação 2007-2010 do MCT (BRASIL, 2007c). Não nos cabe aqui discutir essas políticas e programas como um todo, mas apenas destacar que todas elas buscam aumentar a competitividade das empresas brasileiras reforçando sua capacidade de inovação, elevando os gastos com P\&D das empresas nacionais e a internalização de atividades de pesquisa de empresas estrangeiras, buscando sua maior integração com universidades e institutos de pesquisa e reforçando a infraestrutura de apoio científico e tecnológico às empresas. Em todas elas o Complexo Industrial da Saúde é um setor priorizado (sendo na PITCE apenas o setor de fármacos e medicamentos), tanto pela sua importância intrínseca quanto pelo potencial que apresenta para alavancar conhecimentos e tecnologias estratégicas na matriz produtiva brasileira.

No que diz respeito à infraestrutura de apoio científico e tecnológico a PITCE destaca que:

é importante a criação e o fortalecimento de instituições públicas e privadas de pesquisa e serviços tecnológicos. É necessário estruturar laboratórios nacionais que possam reunir infraestrutura de porte e criar sinergia de pesquisa e desenvolvimento, organizar estágios iniciais de pesquisa empresarial e transferir tecnologia e gestão para o setor produtivo. (BRASIL, 2003)

A Política Nacional de Biotecnologia seinsere em um nível de detalhamento maior. Além da definição de alvos e áreas estratégicos com vistas ao interesse da saúde pública e o fortalecimento da cadeia biotecnológica no país, propõe ações estruturantes, com impacto direto sobre a infraestrutura científica e tecnológica de apoio ao CEIS no que concerne aos investimentos (promover fomento; desoneração tributária, criação de empresas de base tecnológica - EBTs); recursos humanos (formação científica, tecnológica e gerencial, com foco na bioindústria); infraestrutura pública e privada 
(inclui biotérios, bioensaios, testes clínicos e pré-clinicos, coleções, centro depositário de material biológico, redes de P\&D), capacitação em gestão da inovação nas instituições de ciência e tecnologia - ICTs, apoiar incubadoras e arranjos produtivos locais, promover cooperação ICTs - empresa; e marco regulatório (inovação, propriedade intelectual, biossegurança, metrologia, normalização, avaliação de conformidade de material biológico, acreditação).

O Programa Mais Saúde, que orienta as ações do Ministério da Saúde até 2011, no eixo voltado para o Complexo Industrial da Saúde, que tem como diretrizes estratégicas o fortalecimento do Complexo Industrial e de Inovação em Saúde e o aumento da competitividade em inovações das empresas e produtores públicos e privados das indústrias da saúde, propõe para a infraestrutura científica e tecnológica para o CEIS: fomentar redes tecnológicas voltadas à regulação e à qualidade dos produtos de saúde, incluindo laboratórios de testes e certificação de produtos para a saúde; implantar o Centro de Desenvolvimento Tecnológico em Saúde na Fiocruz; fomentar a criação e ampliação de duas redes de pesquisa clínica voltadas para as prioridades do SUS; dois centros de toxicologia; e de uma rede de biotérios.

O Plano de ação do MCT expressa a nova configuração da Política Nacional de Ciência, Tecnologia e Inovação, definindo entre as prioridades estratégicas para o período 2007-2010 a expansão e consolidação do Sistema Nacional de C,T\&I e a promoção da inovação tecnológica nas empresas. No âmbito dessas prioridades destacamos as linhas de ação que dizem respeito à infraestrutura de apoio ao CEIS e ao relacionamento universidade-empresa:

- Formação, qualificação e fixação de recursos humanos para C,T\&I em áreas estratégicas para o desenvolvimento do país e fortalecendo as regiões menos consolidadas do sistema.

- Apoio à infraestrutura da pesquisa científica e tecnológica, favorecendo a integração de grupos e a formação de redes; apoiar grupos emergentes; infraestrutura laboratorial, organizacional de gestão dos institutos públicos de tecnologia.

- Apoio à inovação tecnológica nas empresas: apoio financeiro às atividades de PDI e à inserção de pesquisadores nas empresas; apoio à cooperação entre empresas e ICTs; capacitação de recursos humanos para a inovação; apoiar a criação de novos centros de PDI nas empresas,

- Tecnologia para a novação nas empresas: estruturar o sistema SIBRATEC, formado por conjunto de institutos de pesquisa tecnológica organizados em redes temáticas, para apoio à indústria, priorizando os setores da PITCE. 
- Incentivo à criação e à consolidação de empresas intensivas em tecnologia: apoio a incubadoras e parques tecnológicos, venture capital, uso do poder de compra para estimular o desenvolvimento tecnológico nas empresas nacionais.

No que diz respeito à biotecnologia, em sintonia com a Política de Desenvolvimento da Biotecnologia, a Política Nacional de Ciência, Tecnologia e Inovação tem entre suas metas: induzir até vinte projetos cooperativos ICTs-empresas; desenvolver vinte produtos; concluir a instalação do Centro de Biotecnologia do Amazonas; financiar quatro centros / empresas de desenvolvimento tecnológico para scale-up, incluindo estrutura de BPF e BPL; financiar dez plataformas tecnológicas; criar programa de conformidade de biotérios; induzir e fortalecer centros de excelência em testes pré-clínicos e bioensaios nas diversas regiões do país.

No que diz respeito aos insumos para a saúde, as metas da PNCTI são incentivar o desenvolvimento de produtos e processos em áreas estratégicas para - Ministério da Saúde com vistas à expansão das atividades da indústria brasileira; incentivar a formação de sistemas de inovação, fortalecendo a infraestrutura necessária para o desenvolvimento das plataformas tecnológicas e das cadeias de serviços relacionados com o desenvolvimento de produtos e processos produtivos; incentivar a capacitação de recursos humanos para o gerenciamento empresarial do P,D\&I no setor de insumos para a saúde, estimulando a formação de empreendedores no setor.

$\mathrm{Na}$ área de fármacos e medicamentos, a política em questão propõe incentivar as atividades de pesquisa, desenvolvimento e transferência de tecnologia visando à inovação nas empresas nacionais que atuam em saúde, estimular o controle de qualidade, a realização de ensaios toxicológicos (ensaios pré-clínicos) e clínicos. É conferida ênfase às áreas de biotecnologia, biodiversidade, farmoquímicos e à criação de plataformas tecnológicas com alta relevância para as tendências setoriais de inovação, ao apoio à produção pública de medicamentos e de vacinas e à busca de alvos moleculares mediante o estabelecimento de redes de pesquisadores para certas doenças como as negligenciadas, degenerativas e para a rejeição de transplantes, financiamento de quatro empresas para o escalonamento de moléculas bioativas, quatro laboratórios para ensaios pré-clínicos e até quatro biotérios, além de indicar ações para a aproximação da academia com o setor produtivo para a inovação. No campo regulatório, enfatiza-se a necessidade de uma legislação adequada para o acesso ao patrimônio genético.

Um ponto a se destacar é integração e cooperação interinstitucional entre órgãos federais e entre estes e órgãos estaduais de fomento à ciência tecnologia e inovação e com responsabilidades em políticas setoriais. Outro ponto a se destacar é existência de comitês gestores para todas essas políticas e programas, reunindo todos os atores interessados, públicos e privados. 


\subsection{Marco Regulatório}

O marco regulatório também evoluiu muito nos últimos anos para acompanhar a política de inovação - com destaque para a Lei da Inovação (BRASIL, 2004) e a Lei do Bem (BRASIL, 2005). Trabalha-se, atualmente, na operacionalização do poder de compra do governo para alavancar o desenvolvimento tecnológico no setor.

A Lei de Inovação (BRASIL, 2004) estabeleceu diversos mecanismos para a promoção da inovação no País. Criou condições para a constituição de parcerias estratégicas e a cooperação entre universidades, institutos de pesquisa públicos e as empresas com vistas à intensificação de atividades de P,D\&I e à geração de inovações. Permitiu, ainda, a participação minoritária do governo federal no capital de empresas privadas de propósito específico que visem o desenvolvimento de inovações, além da concessão de recursos financeiros, sob a forma de subvenção econômica, financiamento ou participação acionária, visando ao desenvolvimento de produtos e processos inovadores, além de possibilitar encomendas tecnológicas para soluções de problemas que atendam a objetivos de interesse público.

A Lei do Bem (BRASIL, 2005) concedeu um conjunto de incentivos fiscais às atividades de P,D\&I em empresas, entre eles a dedução, na apuração do imposto de renda, de dispêndios com P\&D, inclusive aqueles com instituições de pesquisa, universidades ou inventores independentes. A despeito de esta Lei beneficiar notadamente as empresas de maior porte que declaram pelo regime de lucro real (em contraposição às que pagam pelo lucro presumido), atua na direção de se criar um ambiente favorável à inovação e aos investimentos nas indústrias intensivas em inovação com a farmacêutica, podendo o benefício chegar a mais de 30\% sobre o lucro apurado (WEISZ, 2006).

\subsection{Financiamento}

No que diz respeito ao financiamento, os orçamentos para a inovação no setor saúde cresceram muito nos últimos anos, com importante participação do Ministério da Saúde em sua provisão e direcionamento. Além disso, os instrumentos de financiamento passaram a se alinhar com as propostas da nova política, buscando a indução das atividades priorizadas na política e em estreita ligação com a política de saúde. Está disponível atualmente um amplo escopo de instrumentos junto às agências federais (CNPq, Finep e BNDES, principalmente) e FAPs, para cobrir toda a cadeia de inovação, incluindo financiamentos reembolsáveis, não reembolsáveis e capital de risco.

Destaca-se aqui o mecanismo do Fundo Nacional de Desenvolvimento Científico e Tecnológico - FNDCT (BRASIL, 2008b) mais diretamente relacionado ao 
financiamento da infraestrutura de apoio ao CEIS - os fundos setoriais. Os fundos setoriais são o principal instrumento do governo federal para implementar a política de C\&T. Sua implementação, a partir de 1999, representou um novo padrão de financiamento do setor, garantindo estabilidade dos recursos para a área — seus recursos vêm de um fundo - FNDCT - formado por contribuições incidentes sobre o resultado da exploração de recursos naturais pertencentes à União, parcelas do Imposto sobre Produtos Industrializados - IPI de certos setores e de Contribuição de Intervenção no Domínio Econômico (CIDE) incidente sobre valores que remuneram o uso ou aquisição de conhecimentos tecnológicos / transferência de tecnologia do exterior.

Uma das premissas básicas dos fundos setoriais é apoiar parcerias entre universidades, centros de pesquisa e setor produtivo, visando aumentar os investimentos privados em P\&D e impulsionar o desenvolvimento tecnológico nos setores considerados. As empresas privadas que quiserem participar, entretanto, têm que entrar associadas a universidades ou institutos de pesquisa - que individualmente ou em parceria, demandam os recursos. A gestão dos Fundos envolve a participação de vários segmentos sociais - governo, academia e setor privado em Comitês Gestores, um para cada Fundo, além de um Comitê central.

São dezesseis Fundos Setoriais de Ciência e Tecnologia, quatorze relativos a setores específicos e dois transversais - um voltado à interação universidade-empresa (Fundo Verde-Amarelo) e o outro destinado a apoiar a melhoria da infraestrutura de ICTs. Com exceção de um, os demais são alocados no FNDCT e administrados pela Finep. O Fundo Setorial de Biotecnologia tem como foco promover a formação e capacitação de recursos humanos; fortalecer a infraestrutura nacional de pesquisa e serviços de suporte; expandir base de conhecimento na área, estimular a formação de empresas de base biotecnológica e a transferência de tecnologias para empresas consolidadas, realizar estudos de prospecção e monitoramento do avanço do conhecimento no setor. O Fundo Setorial da Saúde tem como foco estimular a capacitação tecnológica nas áreas de interesse do SUS e aumentar os investimentos privados em $\mathrm{P} \& \mathrm{D}$.

\subsection{Resultados Alcançados}

Embora estas iniciativas sejam relativamente recentes para uma avaliação de seus resultados, verifica-se efetivamente um maior poder de indução do governo no direcionamento da pesquisa acadêmica, mas o investimento da indústria em P\&D e a infraestrutura científica e tecnológica para apoia-lo avançaram muito pouco. A seguir analisam-se os desafios e oportunidades para avançar mais firmemente nesse sentido, aprofundando as reformas iniciadas, mas apontando também uma série de questões não consideradas ou não resolvidas até o momento. 


\section{3 | DESAFIOS E OPORTUNIDADES (POTENCIALIDADES E DEBILIDADES)}

\section{1 | Pesquisa Científica}

Quanto ao desafio de avançar na pesquisa científica, Guimarães (2004) reconhece que "se não vierem a ocorrer limitações da sistemática de fomento à C\&T e mantido o ritmo atual de crescimento da produção científica brasileira, será possível superar na próxima década vários dos países concorrentes ainda situados a nossa frente, inserindo o Brasil no seleto grupo dos 10 países cientificamente mais desenvolvidos que são os maiores produtores de conhecimentos novos no mundo!" (p.309).

Este sucesso, entretanto, é relativizado, uma vez que:

(...) tanto o desempenho obtido, como a capacidade instalada de pesquisa e bem assim a de capacitação de novos pesquisadores, se situam ainda muito aquém dos índices necessários para o enfrentamento dos gigantescos desafios sociais e econômicos que o País apresenta nesta e em outras áreas. O ritmo de crescimento na capacitação e qualificação de novos pesquisadores pode ser suficiente para manter nosso desempenho atual, mas é insuficiente para a competição, já estabelecida, não apenas com os países mais desenvolvidos, mas especialmente com aqueles outros países em situação semelhante à nossa (...) e que vêm apresentando desempenho superior ao que vimos obtendo (...). (GUIMARÃES, 2004, p.327).

Guimarães (2011) aponta que o programa do CNPq de criação dos Institutos Nacionais de Ciência e Tecnologia (INCTs), por exemplo, poderá contribuir para "um ressurgimento de instituições de pesquisa orientadas por missão, desvinculadas de atribuições acadêmicas em menor ou maior grau" - mais permeáveis à política de indução e inovação, - ao lado do modelo universitário-acadêmico. Destaque-se que um terço dos INCTs aprovados (41 dos 120) tem a saúde humana como tema central (GUIMARÃES, 2011). O autor aponta o crescimento de programas organizados segundo padrões setoriais de forma geral, o que poderia fazer diferença em termos de uma pesquisa mais orientada pela demanda.

Entretanto, segundo Guimarães (2011), o modelo que guia a avaliação da pesquisa praticada pela Capes (que segue a árvore do conhecimento do CNPq, definida segundo critérios teórico-metodológicos e disciplinares) é inadequado para avaliar a pesquisa realizada para atender determinados campos de aplicação, classificada atualmente como "multidisciplinar" e, a despeito de serem portadoras de futuro, em 
muitos casos, como a biotecnologia, a nanotecnologia e as tecnologias da informação, são tratadas como "desviantes" da taxonomia canônica, orientada pela oferta. Por isso, outros critérios de avaliação também precisariam ser incorporados aos acadêmicos hoje existentes.

\subsection{Desenvolvimento Tecnológico}

O grande indutor do desenvolvimento deste segmento parece ser efetivamente o aumento do investimento em P\&D por parte das empresas do setor, que tem crescido, mas muito pouco ${ }^{3}$.

Este maior interesse no investimento em P\&D fez com que algumas empresas começassem a procurar a universidade em busca de projetos, mas esse movimento causa certa frustração nas empresas quando estas verificam a falta de BPL no processo de desenvolvimento realizado, sendo especialmente crítica a falta de rastreabilidade dos projetos. Problemas com propriedade intelectual também são relatados.

Além disso, projetos inovadores encontram sérias barreiras à sua continuidade em direção a um produto pela falta de laboratórios credenciados para a realização dos ensaios pré-clínicos. Devido à falta de demanda, existem muito poucas empresas prestando esse tipo de serviço no Brasil — diferentemente do que ocorre nos países desenvolvidos. Seria importante não só incentivar as empresas existentes a se consolidar e expandir suas atividades como subsidiar a criação de novas empresas voltadas para esse fim. Pelo protagonismo do setor público nesta área, entretanto, seria importante que institutos de pesquisa públicos, como Fiocruz e Butantan, e os novos INCTs desenvolvessem as estruturas e competências para o desempenho dessa atividade.

Neste sentido, o Relatório da ABDI (2009) sobre o Complexo Industrial da Saúde sugere que sejam montados institutos públicos voltados para a transformação da "tecnologia de bancada" em tecnologia industrial e para transferência ao setor produtivo. É importante, entretanto, que esses institutos se organizem em rede, para que possam especializar-se e ganhar escala. O Relatório da ABDI sugere que uma agência de $P \& D$ em saúde teria melhores condições de fazer toda a orquestração envolvida.

Para gerar a demanda necessária à operação dos centros de pré-clínicos, entretanto, seria necessário abri-los ao mercado global de prestação de serviços na área, pois parece improvável que a demanda nacional, de empresas públicas e privadas,

$3 \mathrm{O}$ investimento em $\mathrm{P} \& \mathrm{D}$ por parte das empresas de medicamentos parece responder mais às restrições advindas da adoção da Lei de Propriedade Intelectual e da política de Vigilância Sanitária, que obrigam os produtos farmacêuticos a se posicionarem como inovadores ou genéricos, mais do que às políticas industrial e tecnológica apresentadas. 
os sustentem. Foi este o caminho trilhado pelos centros de pesquisa do segmento de ensaios clínicos, com grande sucesso.

Entretanto, dado que as empresas brasileiras têm como estratégia principal de inovação o desenvolvimento de novas formulações ou combinações de moléculas já no mercado, baseando-se intensivamente em ensaios clínicos, seria necessário também desenvolver esse setor, consolidar a capacitação já existente (execução de ensaios fase III) e desenvolver novas (fase I, por exemplo). Vale lembrar que a competência existente atualmente foi desenvolvida com base no atendimento de demanda estrangeira e esta demanda poderia ser utilizada para alavancar o setor. O desenvolvimento do segmento de ensaios clínicos, entretanto, está praticamente estagnado, pela redução de sua competitividade, causada pelo lento e burocrático processo de revisão ética. Segundo participantes do segmento se esta questão fosse melhorada, os centros brasileiros de pesquisa clínica seriam mais competitivos internacionalmente.

Tornar as atividades de desenvolvimento competitivas internacionalmente poderia garantir o fortalecimento da infraestrutura científica e tecnológica de apoio ao CEIS e torná-lo um incentivo para o investimento do setor produtivo em P\&D. Neste caso, as políticas deveriam ampliar seu foco para contemplar os gargalos apontados no item anterior deste trabalho - importações, retenção de recursos humanos qualificados e agilização e harmonização do processo de revisão ética e sanitária.

Vale ressaltar ainda que a cooperação universidade-indústria é dificultada pelo modelo jurídico e gestão das instituições públicas, sendo difícil fazer o contrato, as relações conflituosas entre os centros de P\&D e o setor privado, tanto em termos de tempo de maturação do projeto como no modo de operação (ABDI, 2009). É difícil fazer os recursos chegarem às equipes que executam os projetos (QUENTAL e SALLES FILHO, 2006). A solução das fundações de apoio atende apenas uma parcela muito pequena das necessidades e é uma solução precária, que não dá segurança aos pesquisadores. Nesse sentido, o Relatório da ABDI (2009) propõe não só um ajuste no modelo jurídico e de gestão de algumas dessas instituições, mas sugere também que se desenvolva um modelo básico de contratualização que dê suporte às negociações.

\subsection{Obstáculos Regulatórios à Condução da P\&D4}

Alguns gargalos regulatórios dificultam o exercício da P\&D no Brasil e, se minimizados, poderiam permitir um melhor desempenho na atividade e uma maior competitividade internacional.

4 Este tópico foi desenvolvido a partir de Baetas et al., 2008. 


\subsection{1 | Importação de insumos para as pesquisas}

As dificuldades com a importação de insumos e materiais para a pesquisa são consideradas um gargalo. Frequentemente as cargas se perdem na alfândega, causando prejuízo e atraso aos projetos. "Esta dificuldade tem também impacto direto sobre a possibilidade de participação em redes de pesquisa internacionais, já que dificulta a troca e o compartilhamento de materiais. Além disso, representa uma desvantagem competitiva da pesquisa brasileira que não consegue ter a agilidade necessária para reagir às publicações internacionais a tempo de participar dos debates científicos lançados" (BAETAS et al., 2008).

Este problema se arrasta há muitos anos e, apesar dos esforços envidados, tem apresentado melhoria lenta.

Atualmente as reclamações voltam-se para a Agência Nacional de Vigilância Sanitária - Anvisa. A Diretoria da agência, na tentativa de responder ao problema, lançou em março de 2008 uma resolução (Anvisa, 2008), que estabelece que, estando a documentação correta, a carga deve ser liberada em até 24 horas. Esta postura da ANVISA parece não encontrar correspondência na atuação das equipes nos portos e aeroportos - para onde convergem as críticas. Grande parte do problema, entretanto, pode estar no desconhecimento dos pesquisadores sobre procedimentos necessários para a importação de produtos sujeitos à vigilância sanitária. São poucas as organizações que dão suporte ao pesquisador nesta área (BAETAS et al., 2008).

\subsection{2 | Retenção dos recursos humanos formados}

Os grupos universitários e os produtores públicos têm dificuldade de reter os recursos humanos formados, contratados, em geral, por meio de bolsas de curta duração. Esta questão é crítica dado que as pesquisas em saúde costumam ser de longa duração. A única alternativa costuma ser a realização de concursos públicos, que nas universidades são em número insuficiente para atender aos grupos de pesquisa, voltando-se mais para completar o quadro de professores das instituições.

Os produtores públicos, que precisam de recursos humanos engajados de forma permanente, também têm problemas para contratação e retenção de mão de obra especializada. 


\subsection{3 | Regulação ética e sanitária}

Com relação aos ensaios pré-clínicos, a regulamentação insuficiente por parte da ANVISA é um dos grandes problemas para o investimento em P\&D. Esta insuficiência de regulação agrega insegurança ao investimento e dificulta a inserção do segmento de pré-clínicos na institucionalidade global. A falta de exigência de BPLs pela Agência impede, por exemplo, a aceitação por parte da OCDE do reconhecimento dado pelo INMETRO para o cumprimento de BPLs em produtos farmacêuticos no Brasil, restrito a agrotóxicos e produtos químicos industriais. O lançamento recente (março/2010) do "Guia para a Condução de Estudos Não clínicos de Segurança Necessários ao Desenvolvimento de Medicamentos", pela ANVISA, embora seja louvável como um primeiro documento de orientação para o segmento, é restrito e não está alinhado com as normas internacionais.

Com relação aos ensaios clínicos, cobra-se melhoria na eficiência operacional do sistema regulatório (sobretudo maior agilidade) e harmonização da legislação que emana dos diferentes órgãos do sistema, o que inclui:

- O sistema de revisão ética, formado pelos Comitês de Ética em Pesquisa - CEPs institucionais e pela Comissão Nacional de Ética em Pesquisa - CONEP, que coordena o sistema. O sistema Ceps-Conep é da órbita do Conselho Nacional de Saúde, órgão de controle social sobre o Ministério da Saúde;

- A regulação sanitária, que emana da Agência Nacional de Vigilância Sanitária - ANVISA, aplicável a qualquer substância que não tenha registro para uso no Brasil;

- Outros órgãos cabíveis quando envolve manipulação genética, como a Comissão Nacional Técnica de Biossegurança CNTBio.

Segundo Baetas et al (2008), no caso da revisão ética, a queixa maior é a demora no tempo para liberação da realização de uma pesquisa, que leva em média oito meses. As críticas são ao seu modelo de funcionamento - dependente de voluntários, com reuniões mensais, sem infraestrutura de funcionamento, adotando processo que não prioriza a comunicação, levando muito tempo para sanar pequenas dúvidas. As criticas ao funcionamento da CNT-Bio seriam da mesma natureza. A ANVISA seria um gargalo no registro do produto. A sugestão é que se estabeleça uma comunicação permanente com as empresas, desde o início dos testes, para que Anvisa e empresas ajustem o procedimento padrão solicitado pela agência para o registro de produtos ao caso específico do produto em questão. (BAETAS et al, 2008). 


\section{4 | CONCLUINDO: CENÁRIOS PARA 2022-2030}

\section{1 | Cenário Inercial}

As perspectivas para a infraestrutura científica e tecnológica de apoio ao CEIS são dependentes das perspectivas do investimento em P\&D das empresas do CEIS. Este investimento vem crescendo muito lentamente e não tem sido capaz de alavancar o desenvolvimento da infraestrutura envolvida. Numa perspectiva inercial, na qual este baixo crescimento persistiria até 2022-2030, prevê-se um cenário parecido com o atual: produção científica relativamente mais forte, porém insuficiente ainda para atender plenamente às necessidades do país; infraestrutura de desenvolvimento tecnológico mais completa, porém ainda insuficiente para ser considerada um incentivo ao desenvolvimento da $\mathrm{P} \& \mathrm{D}$ empresarial.

\subsection{Cenário Desejável e Viável}

Sair dessa trajetória inercial pode requerer diferentes tipos de ações voltadas para transformação da infraestrutura científica e tecnológica em um fator estimulador do incentivo do investimento da indústria em P\&D.

\subsection{1 | Ações estratégicas}

Dado que a indústria não tem capacitação e infraestrutura em P\&D, seu movimento de entrada na atividade passa pelo auxílio da universidade ou de empresas prestadoras de serviços de P\&D no fornecimento de projetos, na assistência técnica, no uso de equipamentos, na prestação de serviços. Tornar essa infraestrutura uma facilidade que incentive as empresas a desenvolver projetos de novos produtos/ processos passa por:

- Dotar os institutos públicos de infraestrutura para atender a indústria e realizar parcerias público-privadas para criação de empresas prestadoras de serviços de $P \& D$ e fornecedoras de insumos para $\mathrm{P} \& D$ na composição dessa infraestrutura (laboratórios de ensaios pré-clínicos certificados em BPLs, suprimento de animais de qualidade, plantas piloto para escalonamento de produção, com marco regulatório permitindo a prestação de serviços e manutenção de pessoal qualificado).

- Tornar estas atividades competitivas internacionalmente para que atendam à demanda de empresas estrangeiras - que terceirizam crescentemente essas atividades, já estando em 
15\% dos ensaios pré-clínicos e 30\% dos clínicos - uma vez que a demanda nacional não as sustentaria. Esta opção só seria possível, entretanto, com mudanças no ambiente regulatório e, principalmente, com uma transformação profunda na forma de encarar o setor de P\&D — como um setor econômico em si, a atividade mais nobre do CEIS no sentido de promover o desenvolvimento. Entretanto, até agora não houve indícios de que vai acontecer.

Ressalte-se que, dado que a inovação é sistêmica, medidas terão maior impacto quanto maior sua abrangência sobre o sistema de inovação. Ilustra-se o ponto de vista com o caso entrada da China no segmento da medicina regenerativa. Elegendo esta área como prioritária, a China conseguiu passar de 37 artigos publicados em periódicos internacionais indexados pelo ISI em 2000, para 1116 em 2008, um crescimento impressionante que a levou à quinta posição no ranking internacional, atrás apenas dos EUA, Alemanha, Japão e Inglaterra. Quanto às aplicações das pesquisas, a China foi o primeiro país a cultivar e reintroduzir tecido cerebral em uma pessoa (que havia sofrido um acidente), criou ossos, pele, músculos e vasos sanguíneos artificiais e transferiu o núcleo de uma célula humana em um óvulo de coelha para produzir células-tronco. A China aprovou também as duas primeiras terapias gênicas do mundo: Gendicine, comercializada pela empresa Sibiono; e Oncorine, comercializada pela Sunway Biotech Co., ambas para câncer - embora haja críticas de que foram comercializados muito rapidamente e sua eficácia seja criticada. Existem várias empresas privadas atuando no segmento, muitas spin-offs de centros de pesquisa, algumas parcerias públicoprivadas, e vários centros de tratamento com células-tronco.

O financiamento governamental na China, substancial, está voltado principalmente para o desenvolvimento (78\% do financiamento), por meio de programas estratégicos, apoiando o setor também com incentivo para repatriação de cientistas e com o estabelecimento de institutos de pesquisa para apoio à indústria - todos os incentivos alinhados (MACMAHON et al., 2010). Comparativamente, as publicações brasileiras na área, também considerada prioritária pelo Ministério da Saúde, saem de um mesmo patamar no ano 2000 e não chegaram a 200 artigos em 2008 (MACMAHON et al., 2010). Vale lembrar que o investimento na pesquisa em medicina regenerativa pela SCTIE/MS tem como justificativa ser esta uma área que está apenas começando, na qual o Brasil ainda teria chances de competir por uma posição de destaque.

Vale à pena ressaltar um nicho de competências a ser explorado: a pesquisa translacional. A pesquisa translacional ou de tradução une diretamente cientistas e médicos que realizam pesquisa clínica, permitindo reunir num mesmo projeto avanços e hipóteses na pesquisa básica e, informações de doenças e terapias observadas pelos médicos da pesquisa clínica. Este modelo, que se contrapõe àquele em que os projetos nascem nos laboratórios e têm a pesquisa clínica apenas como locus de teste para os 
produtos gerados, é a base de novas tecnologias como células-tronco e outras, além de base para o desenvolvimento de uma classe de produtos — os biomarcadores — cada vez mais importantes no desenvolvimento de novos tratamentos. No caso brasileiro, esse modelo seria prioritário também pelo fato de permitir capturar resultados de interesse que algumas moléculas escondem devido ao processo de desenvolvimento e de exigências regulatórias tradicionais focarem somente nas suas indicações principais, permitindo que as empresas nacionais trabalhem com moléculas que já estão no mercado, em um processo de desenvolvimento de menor risco e custo. Assim, o Brasil poderia ter vantagens por sua capacitação em medicina e em pesquisa clínica.

\subsubsection{Medidas de caráter operacional}

Outras medidas, de caráter operacional, podem ser consideradas, já que removem obstáculos à condução da P\&D e obstáculos na relação universidadeempresa, ainda que não mudem a organização atual do sistema. Já foram mencionadas no item anterior, mas vale recapitulá-las aqui, para sistematizá-las.

Dentre os obstáculos à condução da $P \& D$, mencionamos no item anterior que para minorá-los seriam necessárias medidas para facilitar a importação de insumos; para permitir a retenção dos recursos humanos formados; e regulamentação ética e sanitária (BAETAS et al, 2008).

As medidas para reduzir os obstáculos à relação universidade-empresa mencionados passariam por questões como qualidade da pesquisa, confidencialidade das informações e discussões sobre propriedade intelectual (BAETAS et al., 2008); mudanças na forma jurídica e na gestão das universidades e institutos de pesquisa para facilitar a cooperação, definição de modelo básico de contratualização que dê suporte às negociações, promoção do entendimento das expectativas e necessidades das partes envolvidas e criação de estruturas intermediárias para passagem das tecnologias da bancada para o setor industrial (ABDI, 2009).

Para o investimento das empresas em P\&D de uma forma mais sistemática, lembramos que a indústria reclama o aprofundamento da Lei de Inovação e maior agilidade no sistema de patentes.

\subsection{Cenário Pessimista}

O cenário pessimista a ser considerado corresponderia a um retrocesso na direção política de incentivo à inovação e ao CEIS. É pouco provável, mas não impossível. Neste caso, o investimento empresarial em P\&D se manteria nos patamares atuais, assim como a infraestrutura de apoio. As perspectivas para o segmento em 2022-2030 seriam de um gap muito maior com relação aos países desenvolvidos e demais países emergentes. 


\section{5 | REFERÊNCIAS BIBLIOGRÁFICAS}

AGÊNCIA BRASILEIRA DE DESENVOLVIMENTO INDUSTRIAL (ABDI). Relatório de acompanhamento setorial - Complexo da Saúde: equipamentos médicos, hospitalares e odontológicos equipamentos médicos, hospitalares e odontológicos. Volume IV. 2009. Disponível em: <www.abdi.com.br/Estudo/Equipamentos\%20M\%C3\%A9dicos\%20-\%20\%20dez2009.pdf>. Acesso em: 20 out. 2011.

AGÊNCIA NACIONAL DE VIGILÂNCIA SANITÁRIA (ANVISA). Sítio Eletrônico. Disponível em www.anvisa.gov.br. Acesso em 17/01/2007.

AGÊNCIA NACIONAL DE VIGILÂNCIA SANITÁRIA (ANVISA). Relatório de Produtividade dos Centros de Bioequivalênica 2002-2007. Brasília: Anvisa, 2007. Disponível em www.anvisa.gov. br/medicamentos/bioequivalencia/estatisticas/relatorio_2002_2007_consolidado.pdf. Acesso em 25/07/2010.

AGÊNCIA NACIONAL DE VIGILÂNCIA SANITÁRIA (ANVISA). RDC 001/2008. Disponível em www.anvisa.gov.br. Acesso em 15 jun 2009.

AGÊNCIA NACIONAL DE VIGILÂNCIA SANITÁRIA (ANVISA). Centros nacionais de biodisponibilidade/ bioequivalênica certificados. Disponível em www.anvisa.gov.br/ medicamentos/bioequivalencia/centros/nacionais/certificados.asp. Acesso em 25/07/2010.

BAETAS, R.; QUENTAL, C.; BOMTEMPO, J. V. Acelerando a P\&D de uma vacina para a Aids no Brasil. Rio de Janeiro: Abrasco, 2008, (relatório de pesquisa).

BARREIRO, L. Proposta de estruturação de uma plataforma tecnológica para realização de ensaios pré-clínicos na Fundação Oswaldo Cruz. Rio de Janeiro: ENSP/Fiocruz, 2010 (projeto de pesquisa).

BODENHEIMER, T. Uneasy alliance. Clinical investigators and the pharmaceutical industry. New England Journalof Medicine 342:1516-1518. 2000.

BOMTEMPO,JV; BAETAS, R. Desenvolvimento de vacinas no Brasil: uma análise da potencialidade da P\&D e das estratégias de inovação. In: BUSS, P; TEMPORÃO, JG; CARVALHEIRO, JR. Vacinas, soros e imunizações no Brasil. Rio de Janeiro: Editora Fiocruz, 2005.

BRASIL. MINISTÉRIO DA CIÊNCIA E TECNOLOGIA E INOVAÇÃO (MCTI). Ciência, Tecnologia e Inovação para o Desenvolvimento Nacional. Plano de Ação 2007-2010. Documento lançado em 20/11/2007. Brasília/DF. Página web: http://www.mct.gov.br (BRASIL, 2007C)

BRASIL. MINISTÉRIO DA CIÊNCIA E TECNOLOGIA E INOVAÇÃO (MCTI). Fundo Nacional de Desenvolvimento Científico e Tecnológico. Brasília, 2008. Disponível em: <www.mct.gov.br>. Acesso em: 18 jun. 2008. (BRASIL, 2008b)

BRASIL. MINISTÉRIO DA CIÊNCIA E TECNOLOGIA E INOVAÇÃO (MCTI). Estatísticas. Disponível em www.mct.gov.br. Acesso em 16 mai 2011.

BRASIL. MINISTÉRIO DA SAÚDE. Mais Saúde: Direito de Todos 2008-2011. Documento lançado em 05/12/2007. Brasília/DF. Página web: http://www.saude.gov.br (BRASIL, 2007b)

BRASIL. MINISTÉRIO DO DESENVOLVIMENTO, INDÚSTRIA E COMÉRCIO EXTERIOR. Política de Desenvolvimento Produtivo (PDP). Brasília. Disponível em http://www.mdic.gov.br/pdp/ arquivos/destswf1224095287. Acesso em 2008. (Brasil, 2008a) 
BRASIL. PRESIDÊNCIA DA REPÚBLICA. Diretrizes de política industrial, tecnológica e de comércio exterior. Brasília. 2003. Disponível em: <www.camara-e.net/_upload/20031126Diretrizes.pdf>. Acesso em: 20 dez. 2011.

BRASIL. PRESIDÊNCIA DA REPÚBLICA. Lei n. 10.973, de 2 de dezembro de 2004: dispõe sobre incentivos à inovação e à pesquisa científica e tecnológica no ambiente produtivo e dá outras providências. Brasília, 2004. Disponível em:<www.planalto.gov.br/ccivil_03/_ato2004-2006/2004/ lei/l10.973.htm>. Acesso em: 21 jun. 2008.

BRASIL. PRESIDÊNCIA DA REPÚBLICA. Lei n. 11.196, de 21 de novembro de 2005: Brasília, 2005. Disponível em: <www.planalto.gov.br/ccivil_03/_ato2004-2006/2005/lei/111196.htm>. Acesso em: 21 jun. 2008.

BRASIL. PRESIDÊNCIA DA REPÚBLICA. Decreto n. 6.041, de 08 de fevereiro de 2007: institui a política de desenvolvimento da biotecnologia, cria o Comitê Nacional de Biotecnologia e dá outras providências. Brasília, 2007. Disponível em: <http://acessibilidade.mct.gov.br/index.php/ content/view/46880.html>. Acesso em: 19 jun. 2008. (Brasil, 2007a)

BURKE, MA; MATLIN, S. Monitoring financial Health Flows for Health Research 2008. Geneva: Global Forum for Health Research, 2008. Disponível em http://www.globalforumhealth.org/ Media-Publications/Publications.

CONSELHO NACIONAL DE DESENVOLVIMENTO CIENTÍfiCO E TECNOLÓgICO (CNPq). Estatísticas. Disponível em www.cnpq.br. Acesso em: 16 mai 2011.

CRUZ, CHB; CHAIMOVICH, H. Brasil. In: UNESCO. Relatório UNESCO sobre Ciência 2010. Disponível em www.unesco.org/science/psd. Acesso em: 16 mai. 2011

DIMASI, J.; HANSEN, R.; GRABOWSKI, H.; LASAGNA, L. Cost of innovations in the pharmaceutical industry. Journal of Health Economics, 10.1991.

GUIMARÃES, J. A pesquisa médica e biomédica no Brasil: comparações com o desempenho científico brasileiro e mundial. Ciência e Saúde Coletiva, 9 (2):303-27, 2004.

GUIMARÃES, R. Pesquisa em saúde no Brasil: contexto e desafios. Revista de Saúde Pública, São Paulo, v. 40, p. 3-10, 2006.

GUIMARAES, R. Desafios da pós-graduação em saúde humana no Brasil. Rev. Saúde Pública, São Paulo, v. 45, n. 1, Feb. 2011. Disponível em <http://www.scielo.br/scielo.php?script=sci_ arttext\&pid=S0034-89102011000100001\&lng=en\&nrm=iso $>$.

HOSPITAL SÍRIO LIBANÊS. Pesquisa pré-clínica: em busca da competência no país. Ata da reunião de trabalho coordenada pelos Profs. Drs. Jorge Khalil Filho e Regina Scivoletto, realizada em São Paulo/SP, Instituto de Ensino e Pesquisa do Hospital Sírio Libanês, nos dias 7 e 8 de junho de 2006.

KALORAMA. Outsourcing in drug development: the CRO market. Kalorama Information, v.II, 2008. 250 p.

KREGER, J; FELDMAN, N. From mice to men: a preclinical outsourcing market update. Chicago: William Blair \&Company, 2004.

LOUSANA, G. (org). Pesquisa Clínica no Brasil. Rio de Janeiro: Ed. Revinter,2002. 
MACMAHON, DS; THORSTEINSDÓTTIR, H; SINGER, PA; DAAR, AS. Cultivating regenerative medicine in China. Regenerative Medicine, 5 (1), 35-44, 2010.

MERCER MANAGEMENT CONSULTING. Where are the next profit zones in pharmaceuticals? www.mercermc.com - Perspectives / Commentaries 2001.

PAREXEL. Parexel's Pharmaceutical R\&D Statistical Sourcebook 2005/2006. Waltham, MA: Parexel International Corporation, 2005.

PIERONI, JP et al. Terceirização da P\&D de medicamentos: panorama do setor de testes préclínicos no Brasil. BNDES Setorial, n.29, p.131-158, mar.2009.

QUENTAL, C; SALLES FILHO, S. Ensaios clínicos: capacitação nacional para a avaliação de medicamentos e vacinas. Revista Brasileira de Epidemiologia, 9 (4): 408-24, 2006.

SAHOO, A. Pharmaceutical outsourcing strategies: market expansion, offshoring and strategic management in the CRO and CMO marketplace. Business Insights, 2006.

TORRES, LB. INCT de Fármacos e Medicamentos reúne lideranças científicas para traçar Plano de Metas 2009. Disponível em: http://www.inct-inofar.ccs.ufrj.br/ws-inaugural.html

VIANNA, CMM; et al. Brazil: financing resource flows in health R\&D. In: LANDRIAULT, E; MATLIN, S. Monitoring financial Health Flows for Health Research 2009. Geneva: Global Forum for Health Research, 2009. Disponível em http://www.globalforumhealth.org/Media-Publications/ Publications.

WEISZ, J. Mecanismos de Apoio à Inovação Tecnológica. Senai/DN - MCT - Protec. $3^{a}$ Edição. Senai/DN:Brasília/DF. 2006. 